\title{
Correction to: Tuberculosis and viral hepatitis in patients treated with certolizumab pegol in Asia-Pacific countries and worldwide: real-world and clinical trial data
}

Chak Sing Lau ${ }^{1}$ (D) $\cdot$ Yi-Hsing Chen ${ }^{2} \cdot{\text { Keith } \text { Lim }^{3} \cdot \text { Marc de Longueville }}^{4} \cdot$ Catherine Arendt ${ }^{4} \cdot$ Kevin Winthrop $^{5}$

Published online: 2 September 2020

(C) International League of Associations for Rheumatology (ILAR) 2020

\section{Correction to: Clinical Rheumatology}

https://doi.org/10.1007/s10067-020-05248-4

The original published version of the above article contained an error. In the Statistical Analysis section, a minus symbol was use instead of a hyphen in the term "patient-years." The original article has been corrected.

Publisher's note Springer Nature remains neutral with regard to jurisdictional claims in published maps and institutional affiliations.

The online version of the original article can be found at https://doi.org/ 10.1007/s10067-020-05248-4

\section{Chak Sing Lau}

cslau@hku.hk

1 Department of Medicine, Queen Mary Hospital, University of Hong Kong, Pok Fu Lam Hong Kong

2 Taichung Veterans General Hospital, Taichung Taiwan

3 Western Health Rheumatology Unit and AIMSS, Melbourne University, Melbourne Australia

4 UCB Pharma, Brussels Belgium

5 Oregon Health and Science University, Portland OR USA 